\title{
A prospective observational study of thrombocytopenia in high risk neonates in a tertiary care teaching hospital
}

\author{
*Anubha Sharma ${ }^{1}$, Karuna Thapar ${ }^{2}$ \\ Sri Lanka Journal of Child Health, 2015: 44(4): 213-219
}

\begin{abstract}
Objective: To study the incidence, associated risk factors and outcomes of thrombocytopenia in a group of high risk neonates admitted to the Neonatal Intensive Care Unit (NICU) of a tertiary care teaching hospital.
\end{abstract}

Method: A prospective observational study was carried out in the NICU of Sri Guru Ram Dass Institute of Medical Sciences and Research, Amritsar on 100 high risk neonates (intramural + extramural) enrolled consecutively from January to July 2013. Babies of parents who refused to sign the consent form were excluded from the study. Gestational age was calculated by obstetrical estimate according to last menstrual period, combined with ultrasound and/or Ballard scoring. Enrolled neonates were observed prospectively and a platelet count was done at presentation, and subsequently, as and when required. The outcomes of the high risk neonates with thrombocytopenia were assessed. Statistical analysis (Chi square test) was done to find out the association of the risk factors with neonatal thrombocytopenia.

Results: The study population comprised 84 males and 16 females. There were 55 preterm babies and 66 low birth weight babies. There were 11 babies with necrotising enterocolitis, 35 with perinatal asphyxia, 32 with maternal risk factors, 56 with respiratory risk factors, 66 with sepsis, 11 with twin deliveries, 41 with small for gestational age / intrauterine growth retardation (SGA/IUGR), 20 with jaundice, 10 with congenital defects / syndromes and 4 with ABO incompatibility. Incidence of thrombocytopenia among the high risk neonates was 55\%. Perinatal

\footnotetext{
${ }^{1}$ Senior resident, ${ }^{2}$ Professor and Head, Department of paediatrics, Sri Guru Ram Dass Institute of Medical Sciences and Research, Amritsar, India

*Correspondence: anubha.khera@yahoo.in

(Received on 8 November 2014: Accepted after revision on 19 December 2014)

The authors declare that there are no conflicts of interest

Open Access Article published under the Creative

Commons CC-BY-NC-ND Licence. (cc)
}

asphyxia $(\mathrm{P}=0.015)$, maternal risk factors $(\mathrm{P}=0.006)$, respiratory risk factors $(\mathrm{P}=0.035)$, sepsis $(\mathrm{P}=0.016)$ and SGA/IUGR $(\mathrm{P}=0.008)$ were significantly associated with thrombocytopenia. During the study period $8(14.5 \%)$ cases with thrombocytopenia died, $5(9 \%)$ developed intraventricular haemorrhage and $11(20 \%)$ had frank bleeding. Of the 55 high risk neonates with thrombocytopenia $21(38 \%)$ received platelet transfusions and of them $11(52 \%)$ showed improved platelet counts and 4 (19\%) died.

Conclusion: Thrombocytopenia occurred in 55\% neonates admitted to NICU. Perinatal asphyxia, maternal risk factors, respiratory risk factors, sepsis and SGA/IUGR were significantly associated with thrombocytopenia.

(Key words: Thrombocytopenia, neonates, neonatal intensive care unit)

\section{Introduction}

A healthy neonate, even a preterm, has the same mean platelet count as adults and a platelet count less than $150,000 / \mathrm{cu} \mathrm{mm}$ is defined as thrombocytopenia ${ }^{1}$. Thrombocytopenia is present in $1-5 \%$ of newborns at birth and severe thrombocytopenia in $0.1-0.5 \%{ }^{2}$. Thrombocytopenia develops in $22-35 \%$ of all babies admitted to neonatal intensive care units (NICUs), in up to $50 \%$ of those admitted to NICUs who require intensive care and in $50 \%$ of sick preterms ${ }^{3}$. The various grades of thrombocytopenia are: mild (100,000-150,000 per $\mathrm{cu} \mathrm{mm})$, moderate $(50,000-$ $100,000$ per $\mathrm{cu} \mathrm{mm})$ and severe $(<50,000$ per $\mathrm{cu}$ $\mathrm{mm})$. Some authors categorize platelet counts less than 30,000 per cu $\mathrm{mm}$ as severe thrombocytopenia ${ }^{4}$.

The causes are best differentiated by the time of presentation into fetal, early ( $<3$ days of age) and late onset (3-28 days $)^{4}$. Common fetal causes of thrombocytopenia are alloimmune, congenital infections, aneuploidy and autoimmune ${ }^{4}$. Early onset thrombocytopenia is usually secondary to placental insufficiency [e.g. intrauterine growth retardation (IUGR), diabetes, perinatal asphyxia, disseminated intravascular coagulation (DIC), alloimmunity and autoimmunity, congenital infections, thrombosis, bone marrow replacement, metabolic diseases and 
congenital/inherited syndromes $]^{4}$. Late onset thrombocytopenia is often secondary to sepsis or necrotising enterocolitis. Thrombocytopenia not explained by other causes, may indicate an underlying thromboembolic event ${ }^{4}$. The most common cause of severe thrombocytopenia in neonates is immune thrombocytopenia from antiplatelet antibodies across placenta ${ }^{5}$. Low platelet count in an otherwise healthy term newborn is due to neonatal alloimmune thrombocytopenia (NAIT) until proven otherwise ${ }^{4}$.

The only treatment available for neonatal thrombocytopenia, except for immune thrombocytopenia, is platelet transfusion ${ }^{6}$. Neonates should receive $10-15 \mathrm{ml} / \mathrm{kg}$ of cytomegalovirus safe or leukoreduced platelets and they are at increased risk for transfusion-associated graft versus host disease $^{7}$. There are limited Indian prospective studies to identify risk factors associated with neonatal thrombocytopenia and its clinical outcome.

\section{Objective}

To study the incidence, associated risk factors and outcomes of thrombocytopenia in a group of high risk neonates admitted to the Neonatal Intensive Care Unit (NICU) of a tertiary care teaching hospital.

\section{Method}

A prospective observational study was carried out at Level III NICU of Sri Guru Ram Dass Institute of Medical Sciences and Research, Amritsar from January to July 2013, a period of six months. A total of 100 high risk neonates (intramural + extramural) admitted to the NICU during this period formed the study group. The inclusion criteria were:

- Frank bleed.

- Brown or red respiratory tract aspirate.

- A neonate suddenly presenting with decline in haemoglobin and bulging fontanelle / lethargy/ tone changes / pupillary changes suggesting intraventricular haemorrhage (IVH) in a preterm baby, subarachnoid haemorrhage (SAH) or subdural haemorrhage $(\mathrm{SDH})$ in a term baby.

- Positive maternal history viz. pregnancy induced hypertension (PIH), leaking per vagina, infections (Dengue, TORCH etc.), drug history, diabetes, systemic lupus erythematosus (SLE), idiopathic thrombocytopenic purpura (ITP), bleeding per vagina (BPV).
- $\quad$ Positive family history of thrombocytopenia (in any sibling / bleeding tendency in the family).

- Prematurity, intrauterine growth retardation (IUGR) / small for gestational age (SGA), twin deliveries.

- Neonates presenting with jaundice.

- Neonates with a history of perinatal asphyxia

- Neonates presenting with respiratory distress syndrome (RDS), necrotising enterocolitis (NEC) or meconium aspiration syndrome (MAS).

- Neonates presenting with refusal to feed, fever and lethargy or involvement of more than two organ systems suggestive of septicaemia (or sclerema).

- Neonates with positive blood cultures, peripheral blood films suggestive of sepsis, higher total leucocyte counts than recommended for age, raised C-reactive protein (CRP), positive cerebrospinal fluid (CSF) study, conjugated hyperbilirubinaemia

- Syndromic babies (Down, Turner etc.) and neonates with congenital malformations and congenital diseases.

- Neonates undergoing any surgical interventions.

- Neonates receiving mechanical ventilation and neonates with central line in situ

- Sick newborns and with multiple NICU admissions.

The cases were enrolled consecutively after taking written, informed consent from one or both parents after completely explaining the study details to them. Babies of parents who refused to sign the consent form were excluded from the study.

Gestational age was calculated by obstetrical estimate according to last menstrual period, combined with ultrasound and/or Ballard scoring if required. Enrolled neonates were observed prospectively and platelet counts were done at presentation and subsequently as and when required. Platelet count of less than $150,000 / \mathrm{cu} \mathrm{mm}$ was taken as the cut off point for determining thrombocytopenia. All neonates who fulfilled the criteria for admission were shifted to the special care neonatal unit for observation and management. Platelet count was done daily or repeated earlier in sick neonates. Treatment consisted of transfusion of random donor platelet concentrates (RDPCs), when required. Platelet transfusion guidelines were followed ${ }^{4}$. After 
completion of data collection, statistical analysis (Chi square test) was done to find out the association of the risk factors with neonatal thrombocytopenia.

\section{Results}

In our NICU, the incidence of thrombocytopenia was $55 \%$ among the high risk neonates. Mild thrombocytopenia $(100,000-150,000$ per cu mm) was observed in $16.4 \%$ neonates, moderate thrombocytopenia $(50,000-100,000$ per $\mathrm{cu} \mathrm{mm})$ in $36.4 \%$ and severe thrombocytopenia $(<50,000$ per cu $\mathrm{mm})$ in $47.5 \%$. Early onset thrombocytopenia $(<3$ days of age) was seen in $51 \%$ and late onset thrombocytopenia (3-28 days) in $49 \%$. The associations between gender, prematurity $(<37$ weeks gestation), low birth weight $(<2.5 \mathrm{~kg})$, NEC, perinatal asphyxia, maternal risk factors (PIH, 'leaking' per vagina, BPV, diabetes, infection, autoimmune disorders etc.), respiratory risk factors (RDS, MAS, transient tachypnoea of the newborn etc.), sepsis, twin delivery, SGA/IUGR, jaundice, congenital defects/syndromes, ABO incompatibility and neonatal thrombocytopenia in the study population, along with their statistical significance, are shown in Tables 1-13.

Table 1: Association of gender and neonatal thrombocytopenia

\begin{tabular}{|l|c|c|c|c|}
\hline \multicolumn{1}{|c|}{ Sex } & Number & Thrombocytopenia (\%) & No thrombocytopenia (\%) & \multirow{2}{*}{ P value } \\
\hline Male & 84 & $45(53.6)$ & $39(46.4)$ & \multirow{2}{*}{0.511} \\
\hline Female & 16 & $10(62.5)$ & $06(37.5)$ & \\
\hline Total & 100 & 55 & 45 & \\
\hline
\end{tabular}

Table 2: Association of prematurity and neonatal thrombocytopenia

\begin{tabular}{|l|c|c|c|c|}
\hline Prematurity & Number & Thrombocytopenia (\%) & No thrombocytopenia (\%) & \multirow{2}{*}{ P value } \\
\hline Present & 55 & $32(58.2)$ & $23(41.8)$ & \multirow{2}{*}{0.480} \\
\hline Absent & 45 & $23(51.1)$ & $22(48.9)$ & \\
\hline Total & 100 & 55 & 45 & \\
\hline
\end{tabular}

Table 3: Association of low birth weight and neonatal thrombocytopenia

\begin{tabular}{|l|c|c|c|c|}
\hline Low birth weight & Number & Thrombocytopenia (\%) & No thrombocytopenia (\%) & \multirow{2}{*}{ P value } \\
\hline Present & 66 & $38(57.6)$ & $28(42.4)$ & \multirow{2}{*}{0.471} \\
\hline Absent & 34 & $17(50.0)$ & $17(50.0)$ & \\
\hline Total & 100 & 55 & 45 & \\
\hline
\end{tabular}

Table 4: Association of necrotising enterocolitis and neonatal thrombocytopenia

\begin{tabular}{|l|c|c|c|c|}
\hline Necrotising enterocolitis & Number & Thrombocytopenia (\%) & No thrombocytopenia (\%) & \multirow{2}{*}{ P value } \\
\hline Present & 11 & $09(81.8)$ & $02(18.2)$ & \multirow{2}{*}{0.058} \\
\hline Absent & 89 & $46(51.7)$ & $43(48.3)$ & \\
\hline Total & 100 & 55 & 45 & \\
\hline
\end{tabular}

Table 5: Association of perinatal asphyxia and neonatal thrombocytopenia

\begin{tabular}{|l|c|c|c|c|}
\hline Perinatal asphyxia & Number & Thrombocytopenia (\%) & No thrombocytopenia (\%) & \multirow{2}{*}{ P value } \\
\hline Present & 35 & $25(71.4)$ & $10(28.6)$ & \multirow{2}{*}{0.015} \\
\hline Absent & 65 & $30(46.2)$ & $35(53.8)$ & \\
\hline Total & 100 & 55 & 45 & \\
\hline
\end{tabular}

Table 6: Association of maternal risk factors and neonatal thrombocytopenia

\begin{tabular}{|l|c|c|c|c|}
\hline Maternal risk factor & Number & Thrombocytopenia (\%) & No thrombocytopenia (\%) & \multirow{2}{*}{ P value } \\
\hline Present & 32 & $24(75.0)$ & $08(25.0)$ & \multirow{2}{*}{0.006} \\
\hline Absent & 68 & $31(45.6)$ & $37(54.4)$ & \\
\hline Total & 100 & 55 & 45 & \\
\hline
\end{tabular}


Table 7: Association of respiratory risk factors and neonatal thrombocytopenia

\begin{tabular}{|l|c|c|c|c|}
\hline Respiratory risk factor & Number & Thrombocytopenia (\%) & No thrombocytopenia (\%) & P value \\
\hline Present & 56 & $36(64.3)$ & $20(35.7)$ & \multirow{2}{*}{0.035} \\
\cline { 1 - 4 } Absent & 44 & $19(43.2)$ & $25(56.8)$ & \\
\hline Total & 100 & 55 & 45 & \\
\hline
\end{tabular}

Table 8: Association of sepsis and neonatal thrombocytopenia

\begin{tabular}{|l|c|c|c|c|}
\hline \multicolumn{1}{|c|}{ Sepsis } & Number & Thrombocytopenia (\%) & No thrombocytopenia (\%) & P value \\
\hline Present & 66 & $42(63.6)$ & $24(36.4)$ & \\
\hline Absent & 34 & $13(38.2)$ & $21(61.8)$ & 0.016 \\
\hline Total & 100 & 55 & 45 & \\
\hline
\end{tabular}

Table 9: Association of twin delivery and neonatal thrombocytopenia

\begin{tabular}{|l|c|c|c|c|}
\hline \multicolumn{1}{|c|}{ Twin delivery } & Number & Thrombocytopenia (\%) & No thrombocytopenia (\%) & P value \\
\hline Present & 11 & $07(63.6)$ & $04(36.4)$ & 0.542 \\
\hline Absent & 89 & $48(53.9)$ & $41(46.1)$ & 45 \\
\hline Total & 100 & 55 & 45 & 0 \\
\hline
\end{tabular}

Table 10: Association of SGA/IUGR and neonatal thrombocytopenia

\begin{tabular}{|l|c|c|c|c|}
\hline \multicolumn{1}{|c|}{ SGA/IUGR } & Number & Thrombocytopenia (\%) & No thrombocytopenia (\%) & P value \\
\hline Present & 41 & $29(70.7)$ & $12(29.3)$ & \multirow{2}{*}{0.008} \\
\hline Absent & 59 & $26(44.1)$ & $33(55.9)$ & 45 \\
\hline Total & 100 & 55 & & \\
\hline
\end{tabular}

Table 11: Association of jaundice and neonatal thrombocytopenia

\begin{tabular}{|l|c|c|c|c|}
\hline \multicolumn{1}{|c|}{ Jaundice } & Number & Thrombocytopenia (\%) & No thrombocytopenia (\%) & P value \\
\hline Present & 20 & $09(45.0)$ & $11(55.0)$ & 0.315 \\
\hline Absent & 80 & $46(57.5)$ & $34(42.5)$ & 45 \\
\hline Total & 100 & 55 & & \\
\hline
\end{tabular}

Table 12: Association of congenital defects/syndromes and neonatal thrombocytopenia

\begin{tabular}{|l|c|c|c|c|}
\hline Congenital defect/syndrome & Number & Thrombocytopenia (\%) & No thrombocytopenia (\%) & P value \\
\hline Present & 10 & $04(40.0)$ & $06(60.0)$ & \\
\hline Absent & 90 & $51(56.7)$ & $39(43.3)$ & 0.315 \\
\hline Total & 100 & 55 & 45 & \\
\hline
\end{tabular}

Table 13: ABO incompatibility and neonatal thrombocytopenia

\begin{tabular}{|l|c|c|c|c|}
\hline \multicolumn{1}{|c|}{ ABO incompatibility } & Number & Thrombocytopenia (\%) & No thrombocytopenia (\%) & P value \\
\hline Present & 04 & $01(25.0)$ & $03(75.0)$ & \multirow{2}{*}{0.218} \\
\hline Absent & 96 & $54(56.3)$ & $42(43.7)$ & 45 \\
\hline Total & 100 & 55 & & \\
\hline
\end{tabular}

Umbilical catheterisation was carried out in 3 high risk neonates but none of them developed thrombocytopenia. In our study there were 10 ELBW babies (birth weight $<1000 \mathrm{~g}$ ) and all of them $(100 \%)$ had severe thrombocytopenia (platelet count $<50,000 / \mathrm{cu} \mathrm{mm}) .42 .4 \%$ of septic neonates had positive blood cultures. $40.2 \%$ of the septic thrombocytopenic neonates had early onset sepsis and $59.8 \%$ late onset sepsis. Organisms isolated from the blood of septic babies in order of frequency were: Staphylococcus aureus, Klebsiella, Enterobacter, Escherichia coli, Coagulase negative Staphylococcus aureus, Pseudomonas, gram-positive cocci and Candida. The outcomes of the 55 high risk neonates with thrombocytopenia are shown in Table 14. 
Table 14

Outcome of high risk thrombocytopenic neonates

\begin{tabular}{|l|c|}
\hline \multicolumn{1}{|c|}{ Outcome } & No. (\%) \\
\hline Deaths & $08(14.5)$ \\
\hline Intra ventricular haemorrhage & $05(09.1)$ \\
\hline Bleeding & $11(20.0)$ \\
\hline Discharge on request & $07(12.7)$ \\
\hline Left against medical advice & $09(16.4)$ \\
\hline Uneventful/improved with treatment & $15(27.3)$ \\
\hline Total & 55 \\
\hline
\end{tabular}

Of the 55 high risk neonates with thrombocytopenia $21(38 \%)$ received platelet transfusions and of them $11(52 \%)$ showed improved platelet counts, $4(19 \%)$ died, $4(19 \%)$ left against medical advice and 2 (10\%) were discharged on request. All 5 babies with IVH were less than 28 weeks in gestation. The 11 bleeding neonates either bled frankly through feeding tube, oral cavity, endotracheal tube and/or nose or had frank haematuria.

\section{Discussion}

Up to $30 \%$ of NICU patients develop thrombocytopenia at some time during hospital admission $^{3,8,9}$. In our NICU $55 \%$ of high risk neonates developed thrombocytopenia. Platelet transfusions are frequently given to NICU patients and may result in unnecessary transfusions ${ }^{10}$. Improved guidelines are required for safe lower limits for platelet transfusions in stable and sick neonates, effective platelet transfusion protocols in sick neonates and improved therapy for conditions precipitating thrombocytopenia ${ }^{10}$. Bhat $\mathrm{YR}$ et al showed that $57.7 \%$ of thrombocytopenia was associated with the male gender ${ }^{11}$. In our study population there were $84 \%$ males but only $53.5 \%$ of males developed thrombocytopenia compared to $62.5 \%$ of females. Thus gender was not significantly associated with thrombocytopenia $(\mathrm{P}=0.511)$. Beiner ME et al showed that $31 \%$ of preterm babies developed thrombocytopenia ${ }^{12}$. In our study $58.2 \%$ preterm babies developed thrombocytopenia. However, $51.1 \%$ term babies also developed thrombocytopenia. Thus the association of prematurity with thrombocytopenia was not significant $(\mathrm{P}=0.480)$. Christensen $\mathrm{RD}$ et al observed thrombocytopenia in $73 \%$ of the extremely low birth weight (ELBW) population, being more common in the neonates with birth weight $<800 \mathrm{~g}^{13}$. In our study $100 \%$ of ELBW babies had thrombocytopenia. However, low birth weight as a whole was not significantly associated with thrombocytopenia $(\mathrm{P}=0.471)$
Gupta AK et al found no relation between platelet count and type of delivery ${ }^{14}$. Nursen $B$ et al demonstrated a relationship between the severity of thrombocytopenia and the severity and staging of hypoxic ischaemic encephalopathy ${ }^{15}$. In our study perinatal asphyxia was significantly associated with thrombocytopenia $(\mathrm{P}=0.015)$. Maruyama $\mathrm{H}$ et al found growth restriction to be a significantly independent risk factor for thrombocytopeni ${ }^{16}$. In our study SGA/IUGR was significantly associated with thrombocytopenia $(\mathrm{P}=0.008)$. Bhat $\mathrm{YR}$ et al observed that $36 \%$ of neonates born to mothers with PIH had thrombocytopenia ${ }^{17}$. In our study maternal risk factors were significantly associated with thrombocytopenia $(\mathrm{P}=0.006)$.

Gupta AK et al observed that $81.5 \%$ of septic neonates developed low platelet counts ${ }^{14}$. In our study sepsis was significantly associated with thrombocytopenia $(\mathrm{P}=0.016)$. Arif $\mathrm{SH}$ et al observed that Klebsiella was the most commonly isolated organism ${ }^{18}$. In our study the commonest organism isolated was Staphylococcus aureus with Klebsiella taking second place. Bacterial infection causes damage to vascular endothelial lining, thus accelerating adhesion, destruction, and removal of platelets. Viral infection increases platelet destruction due to loss of sialic acid from platelet membrane, increases platelet aggregation, and decreased production from infected marrow ${ }^{19}$. Sepsis also causes DIC, immune-mediated destruction, and decreased production of platelets from infected marrow $^{20}$. Gupta $\mathrm{AK}$ et al observed that $43 \%$ of thrombocytopenic neonates had respiratory risk factors ${ }^{14}$. In our study respiratory risk factors were significantly associated with thrombocytopenia $(\mathrm{P}=0.035)$.

Burrows RF et al showed that thrombocytopenia occurs in twin pregnancy due to plasma dilution ${ }^{21}$. In our study twin delivery was not significantly associated with thrombocytopenia $(\mathrm{P}=0.542)$. Jeremiah ZA et al showed that $19.7 \%$ of the babies with low platelet counts had neonatal jaundice as the risk factor ${ }^{22}$. In our study neonatal jaundice was not significantly associated with thrombocytopenia $(\mathrm{P}=0.315)$. Roberts I et al observed that $90 \%$ of cases of late onset thrombocytopenia were due to necrotizing enterocolitis ${ }^{6}$. In our study NEC was not significantly associated with thrombocytopenia $(\mathrm{P}=0.058)$. Roberts I et al showed that babies born with certain congenital syndromes have late onset thrombocytopenia ${ }^{6}$. In our study congenital defects/syndromes were not significantly associated with thrombocytopenia $(\mathrm{P}=0.315)$. 
Von Lindern JS et al found that $12 \%$ of babies with neonatal thrombocytopenia developed $\mathrm{IVH}^{23}$. In our study $5(9.1 \%)$ high risk babies with neonatal thrombocytopenia developed IVH and all 5 were less than 28 weeks in gestation. This is understandable since the germinal matrix lacks a fibronectin layer in preterm babies. Bonifacio $\mathrm{L}$ et al observed that mucocutaneous bleeding complicated $18.4 \%$ of cases with severe and late-onset thrombocytopenia ${ }^{24}$. In our study $11(20 \%)$ of high risk neonates with thrombocytopenia developed bleeding. Von Lindern JS et al showed that out of all included neonates with thrombocytopenia, 29\% received a platelet transfusion $^{23}$. In our study $21 \quad(38 \%)$ high risk neonates with thrombocytopenia received platelet transfusions.

Platelet transfusions are frequently given to NICU patients with severe thrombocytopenia but no study has assessed whether this is clinically appropriate. Although the widely used liberal triggers for neonatal platelet transfusion reflect available guidelines and represent cautious ('safe') haemostatic practice, they are likely to result in unnecessary transfusion for a significant number of NICU patients. Improved practice requires definition of a safe lower limit for platelet count in stable neonates; effective platelet transfusion strategies for sick neonates; and improved therapies for conditions precipitating severe thrombocytopenia.

\section{Conclusions}

- Thrombocytopenia occurred in $55 \%$ neonates admitted to NICU.

- Perinatal asphyxia, maternal risk factors, respiratory risk factors, sepsis and SGA/IUGR were significantly associated with thrombocytopenia.

\section{References}

1. Veneri D, Franchini M, Randon F, Nichele I, Pizzolo G, Ambrosetti A. Thrombocytopenia: A clinical point of view. Blood Transfusion 2009; 7:75-85.

2. Hohlfeld P, Forestier F, Kaplan C, et al. Fetal thrombocytopenia: a retrospective survey of 5,194 fetal blood samplings. Blood 1994; 84: 1851-6.

3. Castle V, Andrew M, Kelton J, et al. Frequency and mechanism of neonatal thrombocytopenia. Journal of Pediatrics 1986; 108:749-55.

http://dx.doi.org/10.1016/S00223476(86)81 059-9

4. Groves A, Kuschel C. NW Newborn Clinical Guideline: Neonatal Thrombocytopenia. Available from: http://www.adhb.govt.nz/newborn/guideline s/Blood/Platelets/NeonatalThrombocytopeni a.htm

5. Roberts I, Murray N. Neonatal thrombocytopenia. Seminars in Fetal and Neonatal Medicine 2008; 13:256-64. http://dx.doi.org/10.1016/j.siny.2008.02.004 PMid: 18378508

6. Roberts I, Murray N. Neonatal thrombocytopenia: causes and management. Archives of Disease in Childhood Fetal and Neonatal Edition 2003; 88:F359-64 http://dx.doi.org/10.1136/fn.88.5.F359 PMid: 12937037 PMCid: PMC1721612

7. Sola M. Evaluation and treatment of severe and prolonged thrombocytopenia in neonates. Clinical Perinatology 2004; 31(1): $1-14$. http://dx.doi.org/10.1016/j.clp.2004.03.014 PMid: 15183652

8. Andrew M, Castle V, Saigal S, Carter C, Kelton JG. Clinical impact of neonatal thrombocytopenia. Journal of Pediatrics 1987; 110:457-64. http://dx.doi.org/10.1016/S00223476(87)80 517-6

9. Roberts I, Stanworth S, Murray NA. Thrombocytopenia in the neonate. Blood Reviews 2008; 22:173-86.

http://dx.doi.org/10.1016/j.blre.2008.03.004 PMid: 18433954

10. Murray NA, Howarth LJ, McCloy MP, et al. Platelet transfusion in the management of severe thrombocytopenia in neonatal intensive care unit (NICU) patients. Transfusion Medicine 2002; 12:35-41. http://dx.doi.org/10.1046/j.13653148.2002.0 0343.x

PMid: 11967135

11. Bhat YR, Cherian CS, Neonatal thrombocytopenia associated with maternal 
pregnancy induced hypertension, Indian Journal of Pediatrics 2008; 75(6):571-3. http://dx.doi.org/10.1007/s12098-008-0110$\mathrm{X}$

PMid: 18759083

12. Beiner ME, Simchen MJ, Sivan E, et al. Risk factors for neonatal thrombocytopenia in preterm infants. American Journal of Perinatology 2003; 20:49-54.

http://dx.doi.org/10.1055/s-2003-37948

PMid: 12638081

13. Christensen RD, Henry E, Wiedmeier SE, Stoddard RA, Sola-Visner MC, Lambert DK, et al. Thrombocytopenia among extremely low birth weight neonates: data from a multi hospital healthcare system. Journal of Perinatology 2006; 26(6):348-53. http://dx.doi.org/10.1055/s-2003-37948 PMid: 12638081

14. Gupta AK, Kumari S, Singhal A, Bahl A Neonatal thrombocytopenia and platelet transfusion. Asian Journal of Transfusion Science 2012; 6(2):161-4.

http://dx.doi.org/10.1055/s-2003-37948

PMid: 12638081

15. Nursen B, Sukru K, Recep S, Serap U Perinatal asphyxia and thrombocytopenia, O.M.U Tip Dergisi 1999; 16(2);100-5.

16. Maruyamaa H, Thrombocytopenia in Preterm Infants with Intrauterine Growth Restriction Acta Medica Okayama 2008; 62(5); 313-7.

17. Bhat YR, Cherian CS, Neonatal thrombocytopenia associated with maternal pregnancy induced hypertension. Indian Journal of Pediatrics 2008; 75(6):571-3 http://dx.doi.org/10.1007/s12098-008-0110-x PMid: 18759083
18. Arif SH. Ahmad I, Ali SM, Khan HM. Thrombocytopenia and bacterial sepsis in neonates. Indian Journal of Haematology \& Blood Transfusion 2012; 28(3):147-51. http://dx.doi.org/10.1007/s12288-011-0118-7 PMid: 23997450 PMCid: PMC3422386

19. Watts TL, Roberts IAG. Haematological abnormalities in the growth restricted infant. Seminars in Neonatology 1999; 4:41-54. http://dx.doi.org/10.1016/S10842756(99)80 006-2

20. Zipursky A, Palko J, milner $\mathrm{R}$ et al. The haematology of bacterial infections in premature infants. Pediatrics, 1976; 57:83841.

21. Burrows RF, Kelton JG Thrombocytopenia at delivery: a prospective study of 6715 neonates. American Journal of Obstetrics and Gynecology 1990; 162:731-4.

http://dx.doi.org/10.1016/00029378(90)9099 6-K

22. Jeremiah ZA, Oburu JE, Pattern and prevalence of neonatal thrombocytopenia in Port Harcourt, Nigeria; Pathology and Laboratory Medicine International 2010; 2;27-31 http://dx.doi.org/10.2147/PLMI.S9968

23. Von Lindern JS, van den Bruele T, Lopriore $\mathrm{E}$ and Walther F. Thrombocytopenia in neonates and the risk of intraventricular haemorrhage: a retrospective cohort study. BMC Pediatrics 2011; 11:16. http://dx.doi.org/10.1186/1471-2431-11-16 PMid: 21314921 PMCid: PMC3045959

24. Bonifacio L, Petrova A, Nanjundaswamy S, Mehta R. Neonatal thrombocytopenia related outcome in preterms. Indian Journal of Pediatrics 2007; 74:269-76. http://dx.doi.org/10.1007/s12098-007-0042-x PMid: 17401266 